\title{
EFEKTIVITAS PENERAPAN E-MODUL BERBASIS KVISOFT FLIPBOOK MAKER MATERI SATUAN PANJANG KELAS 3 SD
}

\author{
Nurya Oktaviana ${ }^{1}$, Akhmad Nayazik², Handini Arga Damar Rani ${ }^{3}$ \\ 1 Labschool UNNES. \\ Email: nurya.via@gmail.com \\ Diterima: April 2019. Disetujui: Mei 2019. Dipublikasikan: Juni 2019
}

\begin{abstract}
ABSTRAK
Guru berperan dalam membantu proses pengkontruksian pengetahuan siswa, yakni dengan guru tidak mentrasferkan pengetahuan yang dimilikinya, melainkan membantu siswa untuk membentuk pengetahuannya sendiri. Pengetahuan dapat dibentuk siswa berdasarkan pengalaman, kreativitas dan bantuan atau dukungan dari pihak guru, oleh karena itu guru harus mampu menciptakan pembelajaran matematika yang efektif dengan menambahkan konsep pada siswa melalui pendekatan dan media yang sesuai dengan materi, dan perkembangan siswa dalam memahami materi. Pembelajaran interaktif berbasis komputer mampu mengaktifkan siswa untuk belajar dengan motivasi yang tinggi karena ketertarikannya pada sistem multimedia, salah satu modul atau bahan ajar perlu dikembangkan agar siswa menyukai matematika, dan lebih termotivasi dalam belajar mandiri. Penelitian ini bertujuan untuk mengetahui keefektifan penerapan e-modul berbasis Kvisoft Flipbook Maker pada mata pelajaran matematika materi satuan panjang kelas 3 SD, metode pada penelitian ini dilakukan menggunakan metode Research \& Development model ADDIE yang terdiri dari 5 tahap yaitu : 1) Analysis, 2) Design, 3) Development, 4) Implementation, 5) Evaluation. Hasil dari penelitin ini menunjukkan bahwa nilai efektivitas oleh respon guru mendapat skor 90\% dengan kriteria "sangat baik" dan juga respon siswa rata-rata skor 79,27\% dengan kriteria "Layak", berdasarkan hasil tersebut maka disimpulkan bahwa penerapan e-modul berbasis Kvisoft Flipbook Maker efektif digunakan pada materi satuan panjang mata pelajaran matematika kelas 3 SD.
\end{abstract}

Kata kunci: E-Modul, Kvisoft Flipbook Maker, Satuan Panjang.

\begin{abstract}
The teacher plays a role in helping the process of constructing student knowledge, that is, with the teacher not transferring the knowledge he has, but helping students to shape their own knowledge. Knowledge can be formed by students based on experience, creativity and assistance or support from the teacher, therefore the teacher must be able to create effective mathematical learning by adding concepts to students through approaches and media in accordance with the material, and the development of students in understanding the material. Computer-based interactive learning is able to enable students to learn with high motivation because of their interest in multimedia systems, one module or teaching material needs to be developed so that students like mathematics, and are more motivated in independent learning. This study aims to determine the effectiveness of the application of e-modules based on Kvisoft Flipbook Maker on mathematics subjects in unit length 3 grade SD, the method in this study was carried out using the ADDIE model Research \& Development method which consists of 5 stages: 1) Analysis, 2) Design, 3) Development, 4) Implementation, 5) Evaluation. The results of this study indicate that the effectiveness of the teacher's response scores $90 \%$ with the criteria of "very good" and also the response of students to an average score of $79.27 \%$ with the criteria "Eligible", based on these results. Kvisoft Flipbook Maker is effectively used in material for long-term 3rd grade mathematics subjects.
\end{abstract}

Keywords: E-Module, Kvisoft Flipbook Maker, Long Unit. 


\section{PENDAHULUAN}

Berkembangnya ilmu teknologi dan informasi membawa perubahan dan paradigma baru pada learning material dan learning method Darmawan (2012). Produk dari teknologi dan informasi telah memberikan alternatif bahan ajar yang dapat digunakan peserta didik dalam bentuk digital seperti $e$-modul. Pembelajaran interaktif berbasis komputer mampu mengaktifkan siswa untuk belajar dengan motivasi yang tinggi karena ketertarikannya pada sistem multimedia, ungkapan tersebut dikuatkan dengan pendapat Wena (2010) bahwa pembelajaran yang dapat memanfaatkan bahan ajar dengan media komputer akan membuat kegiatan proses belajar menjadi menarik dan menantang bagi peserta didik.

Dari hasil pengamatan dikelas, hal ini disebabkan oleh kurangnya guru mengembangkan penggunaan media dalam pembelajaran sehingga siswa sulit memahami materi yang mengharuskan daya ingat yang kuat, pembelajaran yang diterapkan di atas masih kurang bermakna bagi siswa. Akan sangat kurang efektif jika guru hanya menggunakan bahan ajar yang masih dengan buku, modul dan juga LKS yang begitu membosankan dan tidak mengaktifkan minat siswa untuk belajar.

Berdasarkan permasalahan yang ada maka penulis sangat tertarik untuk mengembangkan e-modul dan ingin mengetahui keefektivan penerapan e=modul berbasis Kvisoft Flipbook Maker pada mata pelajaran matematika materi satuan panjang kelas $3 \mathrm{SD}$ LABSCHOOL UNNES.

Penulis berharap dengan dibuatnya e-modul ini dapat menampilkan teori (konsep awal materi), penjelasan dengan animasi atau media video maupun gambar dan evaluasi yang dapat dipelajari siswa dengan mudah dan efektif. Dan dapat dijadikan refrensi dan motivasi guru dalam menerapkan media interaktif khususnya pada mata pelajaran matematika agar pembelajaran menjadi lebih efektif digunakan, sama halnya bagi siswa bahwa dengan adanya e-modul ini diharapkan dapat membantu meningkatkan pemahaman siswa dan menumbuhkan minat dalam belajar.

\section{METODE PENELITIAN}

Sesuai dengan permasalahan dan tujuan penelitian ini termasuk metode penelitian dan pengembangan (Research and Development). Research and Development adalah metode penelitian yang digunakan untuk menghasilkan produk tertentu, dan menguji keefektifan produk tersebut (Sugiyono, 2013: 297). Dan memilih model ADDIE dalam metode penelitian R\&D Yang mempunyai lima tahapan yaitu: 1) Analysis, 2) Design, 3) Development, 4) Implementation, 5) Evaluation.

\section{Subyek Penelitian}

Penelitian ini dilakukan pada siswa kelas 3B SD LabSchool UNNES, yang menjadi subjek penelitian ini berjumlah 17 siswa.

Teknik yang digunakan dalam penelitian ini adalah teknik pengembangan modul elektronik menggunakan software kvisoft flipbook maker materi satuan panjang dengan tahapan sebagai berikut:

1. Validasi Ahli

Validasi ahli dilihat dari dua aspek yaitu aspek materi dan media. Penskoran angket ini dengan menggunakan rating scale, yaitu instrumen pengukuran non tes yang menggunakan suatu prosedur terukur untuk memperoleh informasi sesuatu yang telah diteliti (widoyoko, 2014: 148). 
Tabel 1. Kriteria Skor Penilaian

\begin{tabular}{cc}
\hline Pernyataan & Skor \\
\hline Sangat layak & 5 \\
Layak & 4 \\
Cukup layak & 3 \\
Kurang layak & 2 \\
Sangat kurang layak & 1 \\
\hline
\end{tabular}

Skor yang diperoleh dari angket ini kemudian di akumulasikan dengan menggunakan rumus:

$$
\%=\frac{n}{N} \times 100
$$

Keterangan:

$$
\begin{array}{ll}
\% & =\text { Presentase skor } \\
\mathrm{n} & =\sum \text { skor } \\
\mathrm{N} & =\sum \text { skor maksimum }
\end{array}
$$

Tabel 2. Kriteria Kelayakan

\begin{tabular}{cc}
\hline Kriteria & Kategori \\
\hline $81-100 \%(\mathrm{~A})$ & Sangat layak \\
$61-80 \%(\mathrm{~B})$ & Layak \\
$41-60 \%(\mathrm{C})$ & Kurang layak \\
$21-50 \%(\mathrm{D})$ & Tidak layak \\
$0-20 \%(\mathrm{E})$ & Sangat tidak layak \\
\hline
\end{tabular}

2. Analisis Tanggapan siswa terhadap EModul

Data peserta didik diperoleh melalui angket tertutup dimana jawaban telah disediakan dan menggunakan rating scale (skala bertingkat). Indikator tanggapan siswa dapat dilihat pada tabel 2.3 sebagai berikut:

Tabel 3. Indikator Tanggapan Peserta didik

\begin{tabular}{cc}
\hline Skala & Kategori \\
\hline 5 & Sangat Setuju \\
4 & Setuju \\
3 & Kurang Setuju \\
2 & Tidak Setuju \\
1 & Sangat kurang Setuju \\
\hline
\end{tabular}

Data tanggapan peserta didik terhadap kelayakan $e$-modul dianalisis dengan rumus:

Keterangan:

$$
\%=\frac{n}{N} x 100
$$


hasil penelitian, pembelajaran matematika menggunakan modul di SD masih kurang maksimal, karena modul digunakan sebagai pengganti pelajaran kosong atau belajar mandiri jadi dalam penggunakan modul masih belum maksimal. Sehingga pembelajaran yang dilakukan belum bisa mencapai indikator yang digunakan.

b. Analisis Kurikulum dan Materi

Analisis kurikulum 2013 Matematika di kelas 3 SD dengan SK (Standar Kompetensi) mendeskripsikan dan menentukan hubungan antar satuan baku untuk panjang, berat dan waktu yang umunya digunakan dalam kehidupan sehari-hari dan menyelesaikan masalah yang berkaitan dengan hubungan antar satuan baku untuk panjang, berat dan waktu yang umunya digunakan dalam kehidupan sehari-hari, yang dibagi menjadi satu KD (Kompetensi Dasar). Dipilih KD mencermati permasalahan sehari-hari yang berkaitan dengan hubungan antar satuan baku untuk panjang, berat dan waktu.

\section{Design}

Tahap Design ini dikenal juga dengan istilah membuat rancangan. Tahap yang perlu dilaksanakan pada proses rancangan yaitu: pertama merumuskan tujuan pembelajaran. Kemudian menentukan strategi pembelajaran yang tepat harusnya seperti apa untuk mencapai tujuan tersebut. Hasil penelitian dan pembahasan akan dijelaskan secara rinci sebagai berikut:

Hasil analisis dan materi kemudian dilakukan merumuskan tujuan pembelajaran yaitu: (1) Dapat memilih alat ukur sesuai dengan fungsinya.; (2) Dapat menggunakan alat ukur dalam pemecahan masalah.; (3) dapat menyesuaikan alat ukur dan benda yang diukur ; (4) Dapat menentukan hubungan antar satuan panjang.; (5) Dapat mengetahui macam alat ukur panjang. Materi dikumpulkan dari berbagai referensi diantaranya Ensiklopedia Matematika Terapan MATEMATIKA DALAM LINGKUNGAN (Math in THE
ENVIRONMENT), Walle, Fathani.

3. Development (Pembuatan draf awal $e$ modul)

Setelah langkah-langkah penyusunan dipenuhi, maka berhasil disusun $e$-modul pembelajaran dengan judul Matematika kelas 3 SD Pengukuran Satuan Panjang. Pembuatan $e$-modul pembelajaran ini menggunakan Kvisoft Flipbook Maker. Adapun komponen dalam $e$-modul Matematika kelas 3 SD Pengukuran Satuan Panjang adalah sebagai berikut:

1. Lembar Peta Konsep.

Lembar ini berisikan tentang Materi yang akan dibahas, KD apa yang dipilih dan indikator pembelajaran.

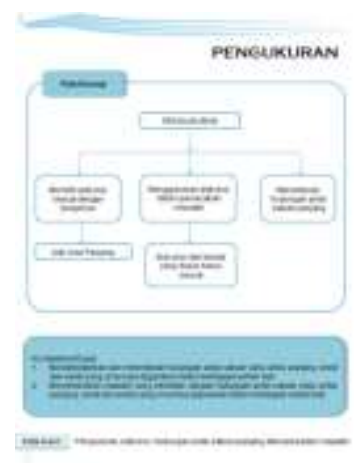

Gambar 1. Lembar Peta Konsep.

\section{Lembar Petunjuk penggunaan LKS}

Petunjuk penggunaan e-modul merupakan lembar yang berisi tentang cara penggunaan e-modul pembelajaran ini. Bertujuan agar siswa paham cara menggunakan e-modul ini.

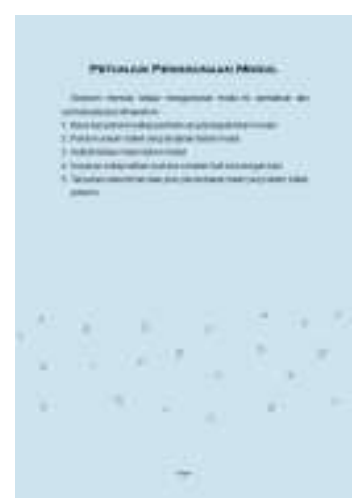

Gambar 2. Lembar Petunjuk Penggunaan Modul 


\section{Lembar Materi}

Materi Hubungan Antar Satuan Panjang merupakan lembar yang berisi tentang isi materi mengenai hubungan antar satuan panjang. sebagai salah satu materi pokok yang dibahas dalam modul ini.

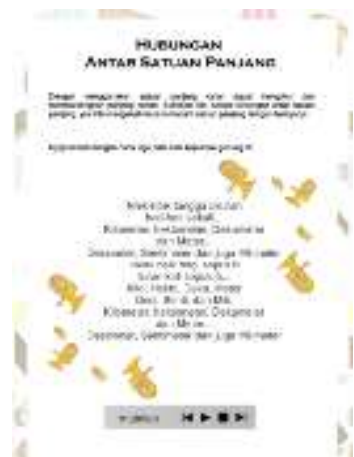

Gambar 3. Lembar Materi

\section{Implementation}

E-modul ini diimplementasikan dalam pembelajaran Matematika kelas 3 di SD LABSCHOOL UNNES. Setelah mendapat persetujuan validator, pemilihan sekolah dengan mempertimbangkan jumlah siswa sebanyak 17 siswa. Sekolah menggunakan modul hanya untuk dikerjakan saat pelajaran kosong ataupun saat guru berlangan hadir. Saat observasi untuk sekolah ini cenderung masih menggunakan modul atau buku hanya sebagai pembantu guru jika berhalangan hadir ataupun kosong dan siswa hanya mengisi latihanlatihan soal yang ada dalam modul tersebut, sehingga peneliti memutuskan untuk menggunakan SD LABSCHOOL UNNES sebagai subjek implementasi $e$ modul pembelajaran. Implementasi dilaksanakan dalam satu pertemuan. Yaitu pada hari Senin, 21 Maret 2019 mulai dari pukul 11:00-12.00.

Persiapan sebelum implementasi dalam pembelajaran dilakukan beberapa hal sebagai berikut.

a. Memberitahukan kepada guru kelas 3B SD LABSCHOOL UNNES tentang isi dan penggunaan e-modul matematika yang akan dipelajari di dalam kelas.

b. Memberikan CD kepada guru kelas 3B SD LABSCHOOL UNNES.

c. Memperbanyak lembar respon siswa untuk mengetahui pendapat mengenai $e$-modul

d. Mempersiapkan alat dan bahan yang akan digunakan dalam pembelajaran dengan menggunakan $e$-modul matematika satuan panjang.

Implementasi diawali dengan perkenalan dan penyampaian rencana kegiatan yang akan dilakukan. Sebelum $e$ modul digunakan peneliti memberi tau bahwa materi pada pertemuan ini adalah pengukuran satuan panjang, dihadiri oleh 17 siswa kelas 3. Kegiatan pertama, peneliti menampilkan $e$-modul secara individu.

Kegiatan selanjutnya peneliti menjelaskan apa yang akan dilakukan menggunakan $e$-modul tersebut dan meminta anak untuk membaca petunjuk penggunaan $e$-modul sebelum mengerjakan apa yang ada dalam $e$-modul tersebut, siswa tidak diperkenankan untuk membuka buku apapun. Peneliti menuntun jalannya pelajaran menggunakan $e$-modul pembelajaran.

Kegiatan ketiga, peneliti tanya jawab kepada siswa bagaimana pembelajarannya menggunakan $e$-modul tersebut.

\section{Evaluation}

Tahap terakhir pengembangan modul matematika adalah $e$-modul berbasis Kvisoft Flipbook Maker yang telah dihasilkan dan di uji cobakan.

Analisis data keefektifan dilakukan bedasarkan penilaian guru kelas dan melalui lembar penilaian $e$-modul. Analisis data keefektifan juga dilakukan berdasarkan penilaian siswa melalui angket respon siswa. Observer (guru kelas) memberikan penilaian yang positif dalam pembelajaran matematika, sebagian besar siswa juga tertarik dan memberikan tanggapan bahwa $e$-modul pembelajaran matematika memudahkan mereka dalam 
memahami materi. Berikut adalah penilaian observer dan respon dari siswa terhadap keefektifan $e$-modul pembelajaran.

1. Penilaian guru (observer)

Lembar penilaian pada aspek ini meliputi 16 indikator yang harus dipenuhi. Hasil penelitian didapatkan skor $85 \%$ dengan penilaian yang menunjukkan kategori baik.

2. Respon siswa.

Respon siswa didapatkan dari angket yang dibagikan oleh peneliti kepada siswa setelah mereka melakukan pembelajaran menggunakan e-modul pembelajaran. Pernyataan dalam angket respon siswa tersebut terdiri dari 11 indikator, hasil dari respon siswa memiliki jumlah rata-rata $79,27 \%$ yang menunjukkan bahwa kategori baik.

Keefektifan pembuatan $e$-modul juga berdasarkan hasil yang didapatkan berdasarkan angket respon guru dan angket respon siswa terhadap $e$-modul yang telah diimplementasikan. Berikut akan dijelaskan secara rinci :

1. Hasil Angket Respon Guru terhadap Media Pembelajaran.

Berdasarkan hasil perhitungan angket respon guru diperoleh skor $85 \%$ dari keseluruhan aspek penilaian dengan kategori baik. Skor ini menunjukkan bahwa guru setuju jika pembelajaran menggunakan $e$-modul yang telah dikembangkan.

2. Hasil Angket Respon Siswa terhadap Media Pembelajaran.

Berdasarkan angket yang telah diisi siswa diketahui bahwa keseluruhan skor rata-rata $79,27 \%$ dari 17 peserta didik dengan kategori baik. Hal inimenunjukkan bahwa siswa sangat setuju belajar menggunakan $e$-modul yang telah dikembangkan.

\section{PENUTUP}

Tampilan hasil pengembangan $e$ modul ini dibuat dengan menggunakan software Kvisoft Flipbook Maker, menggunakan metode Reasearch and Development (R\&D) dan memilih model ADDIE yang terdiri dari lima tahapan yaitu Analysis, Design, Development, Implementation,dan Evaluation. Pada tahap Analysis dilakukan analisis kebutuhan dan dihasilkan analisis kebutuhan akademis. Pada tahap Design dibuat naskah media secara terperinci (storyboard) dan mengumpulkan semua bahan yang dibutuhkan sesuai dengan storyboard serta menyiapkan software yang hendak digunakan yaitu Kvisoft Flipbook Maker. Tahap Development diawali dengan membangun media yang akan dikembangkan sesuai dengan storyboard. Tahap Implementation yaitu dengan mengimplementasikan media yang telah dibuat. Tahap terakhir dari ADDIE yaitu Evaluation. Pada tahap ini dilakukan analisis data dari hasil penggunaan media dan hasil angket yang telah disebarkan.

Berdasarkan tanggapan keseluruhan aspek kuesioner guru dan respon siswa dapat disimpulkan bahwa e-modul berbasis Kvisoft Flipbook Maker efektif untuk digunakan dalam materi satuan panjang pembelajaran matematika.

\section{DAFTAR PUSTAKA}

Darmawan, D. (2012). Pendidikan teknologi informasi dan komunikasi: teori dan aplikasi. PT Remaja Rosdakarya.

Muchtadi, T. R. Sugiyono. 2013. Prinsip Proses dan Teknologi Pangan.

Sudrajat, A. (2014). Pengertian, Fungsi, dan Jenis Media Pembelajaran. Diambil dari https://akhmadsudrajat. wordpress. com/2008/01/12/konsep-mediapembelaja ran/pada, 21 .

Widoyoko, E. P. (2014). Penilaian hasil pembelajaran di sekolah. Yogyakarta: Pustaka Pelajar, 1(2), 8. 